\title{
ASSOCIATION BETWEEN TEACHERS' PERSONALITY TRAITS AND TEACHERS' BURNOUT: MODERATING ROLE OF EMOTIONAL INTELLIGENCE
}

\author{
Asma Asma ${ }^{1^{*}}$, Shakila Malik $^{2}$, Zafar Iqbal ${ }^{3}$, Rahim Khan ${ }^{4}$, Farooq Hussain ${ }^{5}$ \\ ${ }^{1 *}$ Lecturer, Department of Education, Islamia College University Peshawar Khyber Pakhtunkhwa, Pakistan; ${ }^{2} \mathrm{Ph} . \mathrm{D} .$, \\ Scholar, Qurtuba University of Science and Information Technology, Peshawar Khyber Pakhtunkhwa Pakistan; \\ ${ }^{3}$ Assistant Professor, Government College Peshawar Khyber Pakhtunkhwa, Pakistan; ${ }^{4}$ Assistant Professor, Qurtuba \\ University of Science \& Information Technology, Peshawar, Khyber Pakhtunkhwa, Pakistan; ${ }^{5}$ Assistant Professor, \\ Department of physical education and sports Abdul Wali Khan University Mardan, Khyber Pakhtunkhwa, Pakistan. \\ Email: ${ }^{1 *}$ asma@icp.edu.pk, ${ }^{2}$ shakila.malik224@gmail.com, ${ }^{3}$ zafariqbal101275@gmal.com, ${ }^{4}$ dr.rahim43@gmail.com, \\ ${ }^{5}$ farooqhussain@awkum.edu.pk.
}

Article History: Received on $22^{\text {nd }}$ May 2021, Revised on $15^{\text {th }}$ June 2021, Published on $29^{\text {th }}$ June 2021

\begin{abstract}
Purpose of the study: The current study aims to recognize the association between teacher's personality traits and burnout in District Peshawar, Khyber Pakhtunkhwa, Pakistan. The current study predicts the moderating role of emotional intelligence in the relationship between personality traits \& burnout levels of university teachers.
\end{abstract}

Methodology: Quantitative research method was used in this study. Questionnaires were distributed to 317 samples of university teachers in District Peshawar, KP, and Pakistan. To check validity KMO \& Bartlett's test was used. Cronbach Alpha Coefficient was used to test reliability. Meanwhile, hypotheses were tested through regression analysis and t-tests.

Main Findings: It was indicated that openness to experience and neuroticism personality traits predict emotional exhaustion, depersonalization, extroversion \& neuroticism express personal achievement. Emotional intelligence significantly moderates the association between a teacher's personality traits \& burnout. Additionally, it was found that female and private sector university teachers were more burnout than male and public sector university teachers.

Applications of the study: This study will add to the present level of understanding of constructs like personality traits, emotional intelligence, and burnout. The findings of this current study will also help university teachers to know about their dominant personality traits, their emotional level of intelligence. The current study results will help stimulate further research.

Novelty/Originality of the study: To our knowledge, there are only fewer amount of research studies on studying the association between teachers' burnout \& personality traits in university teachers particularly, in the context of Pakistan. Keeping in view that previous studies were not focused on the role of emotional intelligence in the relationship between the above-mentioned dependent and independent variables.

Keywords: Personality Traits, Burnout, Emotional Intelligence, University Teachers, District Peshawar, Pakistan.

\section{INTRODUCTION}

Personality goes beyond the superficial physical qualities of an individual, it refers to the totality or collection of various characteristics. The distinctive, somewhat stable attributes of a person's character (both internal and external) that influence deeds and actions in diverse circumstances are called personality (Schultz and Schultz 2016). The word "personality" comes from the Latin word "persona," which means a cover or mask wore by actors to depict their personalities (Pandey and Kavitha 2015). The Big Five personality trait framework (Costa and McCrae 1992), as cited in (Komarraju, Karau, et al. 2011) has emerged as a robust and parsimonious model for understanding the relationship between personality and a variety of academic behaviors ((Poropat 2009). Being disciplined, methodical, and goaloriented all seem to be examples of conscientiousness. The degree of emotional stability, impulse control, and anxiety is described as neuroticism. Extraversion manifests itself as increased friendliness, assertiveness, and sociability. A deep intellectual curiosity and a preference for novelty reflect openness. Finally, agreeableness relates to the ability and get along with others (Komarraju, Karau, et al. 2011).

From a broader point of view, the concept of burnout connected with life dissatisfaction and workplace depression (Ahola and Hakanen 2007); (Hakanen and Schaufeli 2012); (Toker and Biron 2012) as a basis for workers' disability raises important issues for practitioners, which have extensive implications for employees (including teachers), clients, employers and insurance providers (Hall, Johnson, et al. 2016). There is a need to better understand the risk factors, protective factors against the development of burnout, and various underlying mechanisms. Research and conceptual development that include the testing interplay between personality factors and the burnout experience are needed for firm progress. Attempts to identify risk factors that enhance inclination to job burnout have been mostly limited by a tendency to focus on selected external/environmental than the internal/dispositional contributory factors to the syndrome (Chirkowska-Smolak 2009). To get a better understanding of the process of burnout, the personality-burnout relationship should receive more attention. Several theoretical mechanisms suggest that the various personality traits will 
have an impact on burnout perceptions. Due to the importance of teacher burnout, we came to explore so much about the variables that link personality to burnout in Polish teachers.

The teachers belong to the professional group most exposed to occupational burnout, and in Poland, there are higher and higher rates of burnout in this population (Tucholska 2008). Performing the teaching profession in the contemporary, dynamically changing and complex world is a big challenge and is burdened with high requirements, which makes teachers exposed to experiencing strong and long-lasting stress. On the one hand, teachers have to meet high requirements related to their professional role, i.e.: contact with other people, emotional involvement in work, continuous improvement of professional skills, as well as functioning in a stressful work environment and the need to constantly deal with difficult situations as cited in (Zawadzka, Kościelniak, et al. 2018).

On the other hand, teachers are required to carry out many different tasks and perform many functions simultaneously, such as model function, didactic function, instructional function, and educational function. The model function is related to providing the students with a good example and establishing a constructive personal pattern for them. The didactic function consists of being an efficient educator who, comprehensively and clearly, provides students with reliable knowledge based on the latest scientific achievements. The instructional function is about being a skilled coach who can facilitate and improve the process of acquiring knowledge and basic skills. On the other hand, the educational function refers to being a kind of "a guide", giving support in the field of discovering and stimulating personal potential, supporting the developmental tasks, and sharing responsibility for the development of students (Gaś 2001).

In addition, the teaching profession is characterized by indirect effects of work, and potential rewards are away over time, which can give rise to a lot of frustration. All these factors contribute to the fact that the teachers' professional group is particularly exposed to the teacher's burnout at the workplace. It is also worth emphasizing that the burnout syndrome mostly affects those engaged in work and working in educational institutions where high standards of work matter (Kirenko and Zubrzycka-Maciag 2011). They are deeply involved in their work and carry it out with great passion, but in a situation where they do not see the expected results, they experience a strong disappointment.

Burnout in teachers affects job meaning and satisfaction, but also it makes it impossible for teachers to achieve professional accomplishment, giving us a sense of personal failure. On the psychic level, these teachers suffer from depression, a sense of loneliness, and isolation from other people. Teachers affected by burnout are convinced that they have failed in professional life and have lower self-esteem. They perceive themselves and their accomplishments in a negative light, feel misunderstood by their superiors, and lose their ability (Zawadzka, Kościelniak, et al. 2018). To gain a clear understanding of associations among teachers' personalities, emotional intelligence, and teacher Burnout, this study was conducted. In general motivation behind this study elucidate the functions of various dynamics in teacher burnout, keeping into consideration that former studies produced inconsistent results between burnout $\&$ personality and pay little attention to emotional intelligence. From a theoretical perspective, this mentioned study focuses on important constructs i.e., personality traits, burnout, and emotional intelligence. About contextual contribution, the current study is of great significance as it is a new kind of study in District Peshawar (KP), Pakistan.

\section{Research Objectives}

1 To explore the association between teachers' personality traits \& burnout among university teachers in District Peshawar, KPK.

2 To ascertain the association between teachers' personality traits \& emotional exhaustion among university teachers in District Peshawar, KPK.

3 To find out the association between teachers' personality traits \& depersonalization among university teachers in District Peshawar, KPK.

4 To identify the association between teachers' personality traits \& personal accomplishment among university teachers in District Peshawar, KPK.

5 To explore the difference between public \&private sector university teachers regarding their burnout in District Peshawar, KPK.

6 To find out the difference between male \& female university teachers regarding their burnout in District Peshawar, KPK.

7 To ascertain the moderating role of emotional intelligence between personality traits \& burnout among university teachers in District Peshawar, KPK.

\section{LITERATURE REVIEW}

Emotional stability, extraversion, conscientiousness, agreeableness, self-esteem, Self-Efficacy, locus of control, positive affectivity, negative affectivity, optimism, proactive personality, and hardiness, according to (Alarcon),2009 are related to burnout. They found that personality traits expressed in the Five-Factor Model are strong predictors of each of the burnout dimensions. The relationship between negative experiences and burnout is also controlled by Big-Five traits, suggesting that personality may help to protect against known burnout risks (Bakker, Van Der Zee, et al. 2006). These 
findings also show that employee personality is related to burnout and that the role of personality variables in future burnout research should be addressed.

Shakeel, Khan, et al. 2021 conducted a study to see if there was a relationship between personality traits and burnout in public school teachers. They also explored how school climate affects the relationship between self-efficacy and burnout. For this quantitative study, data was collected from 375 teachers, and the deductive methodology was used. Personal attributes have a massive effect on burnout via self-efficacy, according to the research. This research can help educators, researchers, and practitioners identify and avoid factors that lead to burnout, as well as alleviate burnoutrelated emotions when they occur.

Using Christina Maslach's three-factor burnout model, (Zawadzka, Kościelniak, et al. 2018) discovered the relationship between Big-Five personality traits, perceived self-efficacy, \& characteristics of professional burnout (emotional burnout, depersonalization, perceived lack of own accomplishments). This would be based on facts collected from 271 teachers years of age from 20 to 68 (82 percent of them are female). Furthermore, general self-efficacy beliefs appear (GSEB) to act as a buffer, preventing those with high levels of neuroticism from feeling depressed. It was also observed that GSEB acts as both a mediator and a supporter of Extraversion, Conscientiousness, and Neuroticism in the interaction between them.

The researchers (Savas, Bozgeyik, et al. 2014) looked into the link between self-efficacy and burnout. The sample included 163 randomly selected teachers from various primary and senior public schools. According to the findings of the data analysis, there was a substantial, medium, and negative Teacher self-efficacy and burnout levels get a relationship. (Sarıçam and Sakız 2014) studied Turkish special education teachers (118) to examine if there was a relation between teacher self-efficacy and burnout. According to the data, there were strong relations between teacher self-efficacy and weariness. There were significant differences across genders and branches in terms of burnout and teacher self-efficacy. Self-efficacy was proved to be a powerful predictor of burnout domains using structural equation modeling indices. Self-efficacy beliefs, according to the study, are critical for teachers' emotional involvement, sense of accomplishment, and engagement.

Sulea, Van Beek, et al. 2015 investigated the relationships between three categories of well-being - engagement, boredom, and burnout - and personality, determining if basic need satisfaction has an incremental impact over personality in explaining these well-being types. They discovered that agreeableness and neuroticism were associated with each well-being component in a sample of 255 students, whereas conscientiousness was only associated with engagement and boredom, and extraversion was only connected to burnout.

Skodova and Lajciakova, 2013 investigated the impact of personality variables on the burnout syndrome of 111 university students. Using structural equation modeling indices, self-efficacy was found to be a powerful predictor of burnout domains. According to the study, self-efficacy beliefs are essential for teachers' emotional involvement, sense of accomplishment, and engagement. Burnout was significantly decreased in the experimental group (95 percent confidence interval) after the training, but the control group showed no significant difference. In addition, the experimental group's sense of coherence improved (95 percent confidence interval), although self-esteem levels did not change significantly. Psychosocial training was shown to help students in healthcare professions prevent burnout. In helping professions, psychosocial training is a good method for minimizing burnout.

Prins, van Vendeloo et al. 2019 looked at the links between personality factors, and burnout symptoms among residents. A cross-sectional online poll was undertaken among Dutch residents. One thousand two hundred thirty-one residents took part, with 185 (15.0 percent) of them meeting the burnout criterion. In all disciplines, neuroticism was found to be significantly linked to resident burnout. (van der Wal, Bucx et al. 2016) looked at the impact of personality variables on the incidence of psychological distress and burnout. Burnout and psychological discomfort were detected in $39.4 \%$ and $18 \%$ of all responders, respectively. The most important personality trait that influenced psychological pain and burnout was neuroticism.

In surgical residents, extraversion was linked to a lower risk of burnout. After accounting for gender, overtime, job autonomy, job satisfaction, work-life balance, and perceived learning environment quality, these findings remained extremely significant. Residents' personality features were found to be linked to their likelihood of burnout. Residents who scored high on neuroticism consistently reported higher levels of burnout. According to (Lindeman, Petrusa, et al. 2017), Burnout is common among surgical residents, and it could be affected by personality, emotional intelligence (EI), or work experiences. Significant burnout was noted by $51 \%$ of residents, according to the findings. Higher scores were linked to the female sex. Bivariate analysis revealed that high EI scores, agreeableness, and emotional stability personality traits, and pleasant working experiences were all protective against burnout. Higher EI and positive work experiences were independent predictors of lesser burnout after multivariable adjustment.

Psychological distress, burnout, and compassion fatigue among hospital pharmacists were examined in a cross-sectional study (Higuchi, Inagaki, et al. 2016). According to the study, hospital pharmacists are at a high risk of psychological distress and burnout as a result of their work. Authors have noted the need for counselors to develop skills to deal with stressful situations and avoid burnout. Emotional intelligence may play a role in prevention. (Gutierrez and Mullen 2016) looked at the emotional intelligence of practicing mental health and marital and family counselors and their 
burnout levels. According to the findings, participants' level of emotional intelligence predicted their level of burnout negatively $(\mathrm{r}=-.62, \mathrm{p} .001 ; 38$ percent of variation explained).

Nurse burnout is influenced by personality qualities, and burnout symptoms differ based on the personality features of the nurses. (Molavynejad, Babazadeh et al. 2019) measured burnout levels in oncology nurses to establish burnout stages and examine the association between burnout and demographic and personality variables. Personal accomplishment had a negative link with anxiety and sadness, whereas depersonalization and emotional tiredness exhibited a strong positive link. Personality qualities should be considered in the prevention of burnout syndrome due to their impacts on burnout dimensions. (de Looff, Nijman et al. 2018) investigated the connection between burnout symptoms and the kind and degree of violent behavior experienced by nurses. Personality traits and emotional intelligence (EI) were also explored for their moderating effects. Employee burnout symptoms were found to be positively connected with physical aggression. Stress management abilities, an EI subscale, but not personality, were found to mediate this link.

For the knowledge of the researcher, there is a lesser amount of literature available on the relationship among teachers' personality traits, emotional intelligence, and university teacher burnout in Pakistan. Literature review shows burnout is mainly associated with emotional intelligence. Therefore, as per the importance of personality structure \& emotional intelligence in burnout and due to the paucity of research in this realm, the connection between personality traits and emotional intelligence is attempted to find by us. To develop and propel our perception of the segments affecting teacher burnout, this study was hypothesized. The theoretical model of this study is showed in Figure 1.



Figure 1: The theoretical model

\section{Hypotheses of the Study}

H1: There is a significant association between teachers' personality traits \& burnout among university teachers in District Peshawar, KPK.

H2: There is a significant association between teachers' personality traits \& emotional exhaustion among university teachers in District Peshawar, KPK.

H3: There is a significant association between teachers' personality traits \& depersonalization among university teachers in District Peshawar, KPK.

H4: There is a significant association between teachers' personality traits \& personal accomplishment among university teachers in District Peshawar, KPK.

H5: There is a significant difference between public \&private sector university teachers regarding their burnout in District Peshawar, KPK.

H6: There is a significant difference between male \& female university teachers regarding their burnout in District Peshawar, KPK.

H7: Emotional intelligence moderates the relationship between teachers' personality traits \& burnout among university teachers in District Peshawar, KPK.

\section{METHODOLOGY}

Research Design: In this study quantitative method was used. The study is descriptive that describes the association 
between teacher's personality traits \& burnout in District Peshawar, Khyber Pukhtunkhwa, Pakistan. A 5-point Likert scale questionnaire was used.

Population: Population refers to the group researchers want to generalize research findings to (Muijs 2010). The population of this research included 1,779 teachers. All public and private sector university teachers of District Peshawar, Khyber Pukhtunkhwa, Pakistan constitute the population.

Sample: According to (Kaushik and Mathur 2014) sample is a subset of a population. According to (Sekaran and Bougie 2016) selection of respondents from a population that adequately represents the population is called sampling. Sample of this study consist of 317 university teachers.

Sampling Technique: In this study, a random sampling technique was used.

\section{Determination of Sample Size:}

For determining sample size, (Krejcie and Morgan 1970) were used, who argued that the increasing demand for research has prompted the invention of an efficient approach for determining the sample size needed to be representative of a population. It should be highlighted that as the population increases, the sample size increases.

Variables and \& their measurement criteria: Three main variables were used in this study are

Independent Variable: Personality traits were considered as the independent variable. For measurement of teachers' personality traits, a Big Five Inventory (BFI) developed by John et al, 1991 was used.

Dependent Variable: Teachers' burnout was taken as the dependent variable. This variable was measured using Maslach Burnout Inventory (MBI).

Moderating Variable: Emotional Intelligence was considered as moderating variable. A scale developed by Mehta and Singh, 2013) was used for the measurement of teachers' emotional intelligence.

Nature of Data: Nominal and interval scale is used to formulate the instruments in which overall group responses are examined.

Data Analysis Method: Depending on the nature of the variables t-test, multiple regression analysis, and moderation tests were used for the analysis of data. The collected data were analyzed through SPSS version 23.

Pilot Testing: Pilot testing referred to the procedure of pre-testing of a specific research tool (Polit). According to (Sekaran and Bougie 2016), to make sure that the instrument is valid and free from errors, the pilot study must be conducted before the data collection phase. For pilot testing, 30 university teachers were selected. According to (Dillman 2007), to identify any misinterpretation of queries by the respondents, the Pilot study is important. The pilot test demonstrated that the construct is valid and reliable while allowing for the research tool to be refined (Dikko 2016).

Reliability: According to (Heale and Twycross 2015), reliability refers to when an instrument for data collection produces the same results when repeated in a different situation. Cronbach's alpha values are used to know whether this study will produce stable and reliable results under changed conditions. Reliability found .941 which is considered very good (Fisher 2007).

Table 1: Cronbach's Alpha Coefficient

\begin{tabular}{lcc}
\hline Constructs & N & Cronbach's alpha Score \\
\hline Personality Traits & 31 & .916 \\
\cline { 2 - 3 } Emotional intelligence & 34 & .941 \\
\cline { 2 - 3 } Burnout & 22 & .801 \\
\hline
\end{tabular}

According to the above table 1 , the reliability test for three variables resulted in a score of $(\mathrm{r}=.916, .941, .801)$ for Personality Traits, Emotional intelligence, and Burnout respectively. The scores higher than 0.70 are acceptable.

Validity: According to (Joppe 2000), validity refers to the extent that the research instrument measures which it was planned to measure". Validity was checked through factor analysis.

Table 2: Factor analysis for Personality Traits

\begin{tabular}{lll}
\hline \multicolumn{3}{l}{ KMO and Bartlett's Test } \\
\hline Kaiser-Meyer-Olkin Measure of Sampling Adequacy. & .8765 \\
\hline \multirow{3}{*}{ Bartlett's Test of Sphericity } & Approx. Chi-Square & 1210.430 \\
\cline { 2 - 3 } & Df & 28 \\
\cline { 2 - 3 } & Sig. & .000 \\
\hline
\end{tabular}

KMO and Bartlett test from table 2 indicate that the value of the KMO test has been found more than .70 which means that the factor analysis is suitable and may be used in the study. 
Table 3: Factor analysis for Emotional intelligence

\begin{tabular}{lll}
\hline \multicolumn{3}{l}{ KMO and Bartlett's Test } \\
\hline Kaiser-Meyer-Olkin Measure of Sampling Adequacy. & .804 \\
\hline \multirow{3}{*}{ Bartlett's Test of Sphericity } & Approx. Chi-Square & 1846.340 \\
\cline { 2 - 3 } & Df & 190 \\
\cline { 2 - 3 } & Sig. & .000 \\
\hline
\end{tabular}

KMO and Bartlett test from table 3 indicate that the value of the KMO test has been found more than .70 which means that the factor analysis is suitable and may be used in the study.

Table 4: Factor Analysis for dependent variable Teachers' Burnout

\begin{tabular}{lll}
\hline \multicolumn{3}{l}{ KMO and Bartlett's Test } \\
\hline Kaiser-Meyer-Olkin Measure of Sampling Adequacy. & .8765 \\
\hline \multirow{3}{*}{ Bartlett's Test of Sphericity } & Approx. Chi-Square & 1210.430 \\
\cline { 2 - 3 } & Df & 28 \\
\cline { 2 - 3 } & Sig. & .000 \\
\hline
\end{tabular}

The table above gives a reflection on KMO \& Bartlett's test and P-Value was found <0.01, indicating variability (Kaiser Mayer sampling adequacy measure $=0.875$.

\section{Data collection procedure}

The researcher administered 317 questionnaires among university teachers in district Peshawar KP citizens whose ages range from 25 to 60 . Respondents filed a questionnaire containing series of questions. The questionnaire consisted of 94 questions and was divided into four sections. Section A consists of seven questions, to know about respondent's demographic profiles. Demographic variables include gender, university, qualification, experience, age, designation, marital status. Section B (thirty-one questions) were about respondents' response towards personality traits. Section C of twenty-two questions determined teachers' perception of burnout. In Section D, a new set of thirty-four questions was about teachers' emotional intelligence. To calculate the response of respondents five-point Likert Scale was used in which 5 symbolizes strongly agree and 1 denotes strongly disagree. In this way, each question is scaled in which higher score values direct a positive attitude about the main variables of the study.

\section{RESULTS/FINDINGS}

\section{Hypothesis Testing}

Association between teachers' personality traits \& burnout was tested and results are presented below.

H1: There is a significant association between personality traits and burnout among university teachers

Table 5: Model Summary

\begin{tabular}{ccccccc}
\hline Model & R & R Square & Adjusted R square & Std. The error of the Estimate & Durbin-Watson & F \\
\hline 1 & .448 & .201 & .195 & 8.302 & 1.63 & 37.12 \\
\hline
\end{tabular}

\section{Coefficient}

\begin{tabular}{cccccc}
\hline Model & \multicolumn{1}{c}{ Unstandardized Coefficients } & Standardized Coefficients & & \\
\hline Constant & B & Std. Error & Beta & T Value & Sig \\
\hline & 32.409 & 7.11 & & 4.55 & .00 \\
& .442 & 0.073 & .448 & 6.09 & .00 \\
\hline
\end{tabular}

\section{a. Predictor Variable: Personality Traits}

b. Dependent Variable: Burnout

Table 5 illustrated that $\mathrm{R}$ value $=.448$ and $\mathrm{R}$ square value $=0.201$ which specifies that teachers" personality traits explain 20.1 percent variations in teachers' burnout. F-statistic value of 37.12 shows that the selected model is fit. Beta value shows that .448 of change in burnout is caused by a unit change in personality traits. The above table shows that $\mathrm{p}=.00$ which is acceptable as $\mathrm{p}<0.05$. Since our H1 is accepted.

H2: There is a significant association between teachers' personality traits \& emotional exhaustion among university teachers

Table 6: Regression analysis of Emotional Exhaustion and Personality Traits

Model Summary (1) 


\begin{tabular}{ccccccc}
\hline Model & R & R Square & $\begin{array}{c}\text { Adjusted R } \\
\text { Square }\end{array}$ & $\begin{array}{c}\text { Std. The error of } \\
\text { the Estimate }\end{array}$ & F & Sig. \\
\hline 1 & $.439 \mathrm{a}$ & .192 & .183 & .62268 & 20.149 & $.000 \mathrm{~b}$ \\
\hline
\end{tabular}

a. Predictors: (Constant), Neuroticism, Conscientiousness, Agreeableness, Openness, Extraversion

\section{Coefficients}

\begin{tabular}{|c|c|c|c|c|c|c|}
\hline \multirow[t]{2}{*}{ Model } & & \multicolumn{2}{|c|}{$\begin{array}{l}\text { Unstandardized } \\
\text { Coefficients }\end{array}$} & \multirow{2}{*}{$\begin{array}{l}\text { Standardized } \\
\text { Coefficients } \\
\text { Beta } \\
\end{array}$} & \multirow[t]{2}{*}{$\mathbf{T}$} & \multirow[t]{2}{*}{ Sig. } \\
\hline & & B & Std. Error & & & \\
\hline \multirow{6}{*}{1} & (Constant) & 1.841 & .288 & & 6.382 & .000 \\
\hline & Openness & .341 & .221 & .419 & 3.733 & .002 \\
\hline & Conscientiousness & .476 & .128 & .419 & 3.053 & .000 \\
\hline & Extraversion & -2.042 & .739 & -1.563 & -2.764 & .006 \\
\hline & Neuroticism & 1.778 & 5.566 & 1.418 & 3.142 & .002 \\
\hline & Agreeableness & -.109 & .048 & -.109 & -2.256 & .025 \\
\hline
\end{tabular}

a. a. Dependent Variable: Emotional Exhaustion

b. Predictors: (Constant), Neuroticism, Conscientiousness, Agreeableness, Openness, Extraversion

From the model, it is evident that the adjusted $\mathrm{R}$ square is .183. It means that personality traits can account for almost $18 \%$ of the variation in teachers' emotional exhaustion. Above table indicating that significant value for openness $=$ .002 , consciousness $=.000$ and neuroticism $=.002$ which means that the above mentioned dimensions of personality does have significant relationship with university teachers' emotional exhaustion while extroversion= .00 and agreeableness $=.025$ proven insignificant relationship between said variables.

H3: There is a significant association between teachers' personality traits and depersonalization among university teachers

Table 7: Regression analysis of depersonalization and Personality Traits

Model Summary (2)

\begin{tabular}{ccccccc}
\hline Model & R & R Square & $\begin{array}{c}\text { Adjusted R } \\
\text { Square }\end{array}$ & $\begin{array}{c}\text { Std. The error of } \\
\text { the Estimate }\end{array}$ & F & Sig. \\
\hline 1 & $.616 \mathrm{a}$ & .380 & .372 & .37549 & 51.809 & $.000 \mathrm{~b}$ \\
\hline
\end{tabular}

a. Predictors: (Constant), Neuroticism, Conscientiousness, Agreeableness, Openness, Extraversion

\section{Coefficients}

\begin{tabular}{|c|c|c|c|c|c|c|}
\hline \multirow{2}{*}{\multicolumn{2}{|c|}{ Model }} & \multicolumn{2}{|c|}{$\begin{array}{c}\text { Unstandardized } \\
\text { Coefficients }\end{array}$} & \multirow{2}{*}{$\begin{array}{c}\begin{array}{c}\text { Standardized } \\
\text { Coefficients }\end{array} \\
\text { Beta } \\
\end{array}$} & \multirow[t]{2}{*}{$\mathbf{T}$} & \multirow[t]{2}{*}{ Sig. } \\
\hline & & $\mathbf{B}$ & Std. Error & & & \\
\hline \multirow{6}{*}{1} & (Constant) & .614 & .174 & & 3.530 & .000 \\
\hline & Openness & -.112 & .067 & -.141 & -1.658 & .098 \\
\hline & Conscientiousness & -.121 & .077 & -.155 & -1.576 & .116 \\
\hline & Extraversion & .635 & .446 & .707 & 1.426 & .155 \\
\hline & Agreeableness & -.452 & .341 & -.524 & -1.325 & .186 \\
\hline & Neuroticism & .786 & .050 & .609 & 15.598 & .000 \\
\hline
\end{tabular}

a. Dependent Variable: Depersonalization

b. Predictors: (Constant), Neuroticism, Conscientiousness, Agreeableness, Openness, Extraversion

Adjusted R2is above table is .372. This shows that personality traits can explain $37 \%$ of the variation in depersonalization. Results showing that neuroticism was found to be statistically significant with depersonalization $(\mathrm{p}=.000)$. On the other hand, four dimensions of teachers' personality were insignificant based on statistics evidence (openness $\mathrm{p}=.098$, consciousness $\mathrm{p}=.116$, extroversion $\mathrm{p}=.155$, and agreeableness $\mathrm{p}=.186$ ).

H4: There is a significant association between teachers' personality traits and personal accomplishment among university teachers

Table 8: Regression analysis of personal accomplishment and Personality Traits

Model Summary (3) 


\begin{tabular}{llllllll}
\hline Model & R & R Square & $\begin{array}{l}\text { Adjusted } \\
\text { Square }\end{array}$ & $\begin{array}{l}\text { Std. The error of } \\
\text { the Estimate }\end{array}$ & F & Sig. \\
\hline 1 & $.820 \mathrm{a}$ & .673 & .669 & .20564 & 174.263 & $.000 \mathrm{~b}$ \\
\hline
\end{tabular}

a. Predictors: (Constant), Neuroticism, Conscientiousness, Agreeableness, Openness, Extraversion

\section{Coefficients}

\begin{tabular}{|c|c|c|c|c|c|c|}
\hline \multirow[t]{2}{*}{ Model } & & \multicolumn{2}{|c|}{$\begin{array}{c}\text { Unstandardized } \\
\text { Coefficients }\end{array}$} & \multirow{2}{*}{$\begin{array}{c}\begin{array}{c}\text { Standardized } \\
\text { Coefficients }\end{array} \\
\text { Beta } \\
\end{array}$} & \multirow[t]{2}{*}{$\mathbf{T}$} & \multirow[t]{2}{*}{ Sig. } \\
\hline & & B & Std. Error & & & \\
\hline \multirow{6}{*}{1} & (Constant) & .274 & .095 & & 2.881 & .004 \\
\hline & Openness & -.019 & .0373 & -.031 & -.501 & .617 \\
\hline & Conscientiousness & -.039 & .042 & -.066 & -.921 & .357 \\
\hline & Extraversion & .766 & .027 & .813 & 28.023 & .000 \\
\hline & Agreeableness & -.194 & .187 & -.297 & -1.035 & .301 \\
\hline & Neuroticism & -.160 & .048 & -.160 & -3.354 & .001 \\
\hline
\end{tabular}

a. Dependent Variable: Personal Accomplishment

b. Predictors: (Constant), Neuroticism, Conscientiousness, Agreeableness, Openness, Extraversion

It can be seen in the third model, that the adjusted $\mathrm{R}$ square (.669) explains that $66 \%$ variation in personal accomplishment is caused by personality traits. Findings illustrate that two personality traits i.e. extroversion $\mathrm{p}=.000$ and neuroticism $\mathrm{p}=.001$ were found in significant connection with personal accomplishment. Furthermore, it was found that openness $(p=.617)$, consciousness $(p=.357)$, and agreeableness $(p=.301)$ have no link with personal accomplishment.

H5: There is a significant difference between public \& private university teachers regarding their burnout District Peshawar, KPK

Table 9: Significant difference between public and private sector university teachers regarding their burnout

\begin{tabular}{lllllll}
\hline Variable & University & Mean & SD & F & t-value & Sig. \\
\hline Burnout & Public & 92.78 & 7.23 & 7.20 & & .000 \\
\hline & Private & 102.63 & 8.7 & 3.75 & 7.54 & .000 \\
\hline
\end{tabular}

A significant difference was found between public and private sector university teachers concerning their burnout in District Peshawar, KPK, as results prove $(\mathrm{p}=.000)$. Further, it was seen that teachers of the public university have low burnout levels as compared to teachers of a private university.

H6: There is a significant difference between male \&female university teachers regarding their burnout in District Peshawar, KPK

Table 10: Significant difference between male and female university teachers regarding their burnout

\begin{tabular}{lllllll}
\hline Variable & University & Mean & SD & F & t-value & Sig. \\
\hline Burnout & Male & 1.9678 & .32652 & .520 & & .000 \\
\hline & Female & 2.1341 & .37827 & 4.757 & 4.870 & .000 \\
\hline
\end{tabular}

It is cleared from the above table that showed a significant difference between male and female university teachers concerning their burnout in District Peshawar, KPK. It was found that female teachers were more burnout than male teachers as the p-value is less than .005 ( $\mathrm{p=}=.000)$. Further, it was seen that private sector university teachers were more burnout than public sector university teachers.

\section{H7: Emotional intelligence significantly moderate Relationship Between teachers' personality traits \& burnout}

Table 11: Moderation Effect of Emotional Intelligence on the Relationship between Personality Traits and burnout

\begin{tabular}{ccccccccc}
\hline Model & R & R2 & Adj.R2 & R2 Change & F. Change & Df1 & Df2 & Sig.F Change \\
\hline 1 & .448 & .201 & .195 & .201 & 37.12 & 1 & 148 & .00 \\
\hline 2 & .492 & .242 & .041 & .041 & 8.02 & 1 & 147 & .005 \\
\hline
\end{tabular}

The moderating effect of the emotional intelligence relationship between teachers' personality traits \& burnout has shown in table 11 . The above table shows that the change in $\mathrm{R}$ square value is $4.1 \%$ which means that .041 variation in the $\mathrm{R} 2$ value and change in $\mathrm{F}$ statistic value $=8.02$. It means that by the addition of moderating variable $4.1 \%$ increase occurs in variation. It is evident from the results that Sig. F Change is .005 indicating the model is statistically significant as $\mathrm{p}<.05$. Hence proved from table 11 that emotional intelligence moderate relationship between teachers' personality traits \& burnout. Therefore H4 is accepted. 


\section{DISCUSSION/ANALYSIS}

This study put forward seven goals. The first goal test association between personality traits \& teacher burnout. The second goal confirmed the relationship between personality facets \& emotional exhaustion of teachers. The third goal is to validate the relationship between personality dimensions \&depersonalization. The fourth goal is to determine the relationship between traits of personality and personal accomplishment. The fifth and sixth objective is about the significant difference between private\& Public Sector University teachers regarding their burnout, a significant difference between male-female university teachers concerning burnout respectively. Finally to investigate the moderating role of emotional intelligence in the association between teachers' personality traits \& burnout among university teachers in District Peshawar, KPK, Pakistan.

In hypothesis 1, the study investigated the personality aspects that affect university teachers' burnout level in districts Peshawar in terms of openness, extroversion, agreeableness, consciousness \&neuroticism. As regards our first hypothesis we concluded that personality traits can predict teacher burnout. This result is consistent with (Cano-García, Padilla-Muñoz et al. 2005) and (Fontana and Abouserie 1993). The second hypothesis investigated the association between personality traits and teachers' emotional exhaustion.

For the investigation of the $\mathrm{H} 2$ hypothesis, five sub-hypotheses were planned as follows. The outcome of the relationship between openness to experience personality traits and emotional exhaustion was measured by hypothesis $\mathrm{H} 2$. A is found positive and significant through regression analysis which is supported by the $\mathrm{p}$-value $(\mathrm{P}<.05)$ at the regression weight .341. It is validated that if the openness to the experience personality trait of university teachers in District Peshawar enlarges by 1 unit, the emotional exhaustion also enlarges by .341 . The hypothesis $\mathrm{H} 2$. Bis presenting the positive significant results of the relationship between consciousness personality trait and emotional exhaustion since the regression weight .476 indicates the positive influence of consciousness on emotional exhaustion and change of .476 independent decision-making style occurs due to 1 unit change in consciousness. The results of hypothesis H2.C presented a negative and significant relationship of extroversion personality trait and emotional exhaustion as $\mathrm{p}<0.05$ at regression weight -2.042 which implies that due to 1 unit increase in extroversion, the emotional exhaustion will move downward by -2.042 . The results of H2.C have been established consistent with the results of (Cano-García, PadillaMuñoz, et al. 2005) and (Fontana \& Abousaarie, 1993) who found a negative relationship between emotional exhaustion and extroversion. The results of hypothesis H2. D indicates a negative and significant relationship between agreeableness personality trait \& emotional exhaustion at $\mathrm{p}<0.05$ at regression weight -.109 which explains the inverse change -.109 comes in emotional exhaustion due to one unit upward change in an agreeableness personality trait. The hypothesis H2. E is presenting the positive but significant results of the association between neuroticism personality trait \&emotional exhaustion of university teachers. Since the regression weight of 1.778 indicates a positive influence of neuroticism personality trait on emotional exhaustion. The result of this hypothesis has been found consistent with the study of (Cano-García, Padilla-Muñoz, et al. 2005) and (Fontana \& Abousaarie, 1993). In the same way, they found a significant and positive relationship between emotional exhaustion and neuroticism.

The association between personality traits and teacher's depersonalization is the 3rd hypothesis. For the investigation of the H3 hypothesis, five sub-hypotheses were intended as follows. H3. A hypothesis is checked through regression analysis which was the outcome of the relationship between openness to experience personality trait and depersonalization was measured by hypothesis H3. A is found negative and significant through regression analysis which is supported by the $\mathrm{p}$-value $(\mathrm{P}<.05)$ at the regression weight -.112 . It is validated that if the openness to experience personality trait of university teachers in District Peshawar enlarges by 1 unit, the depersonalization decrease by -.112. Some of the previous studies did not agree with these results. For instance, (Cano-García, Padilla-Muñoz, et al. 2005) stated that lecturers who are interested in different practices can accept challenges and show a low level of depersonalization. Hypothesis H3. Bis presenting the negative insignificant results of the relationship between consciousness personality trait and depersonalization which is supported by the $\mathrm{p}$-value $(\mathrm{P}>.05)$ since the regression weight -.121 indicates the negative influence of consciousness on depersonalization and change of -.121 in depersonalization occurs due to 1 unit change in consciousness. The results are consistent with Fontana and Abousaarie (1993) and Cano-Garcia, Padilla-Munoz, and Carrasco-Ortiz (2005). Teachers who possess low scores in conscientiousness are more susceptible to be depersonalized as these people are somewhat less reliable, aimless, careless, disorganized, late, and lazy. The results of hypothesis H3.C presented a positive and insignificant relationship of extroversion personality trait and depersonalization as $\mathrm{p}>0.05$ at regression weight .635 which implies that due to a 1 unit increase in extroversion, the depersonalization will move upward by .635 . The results of hypothesis H3. D indicates a positive and insignificant relationship between agreeableness personality trait and depersonalization at $\mathrm{p}>0.05$ at regression weight -.452 which explains the inverse change of -.452 comes in depersonalization due to one unit upward change in an agreeableness personality trait. The result of the H3.D hypothesis finds support in the literature for example in a study by Fontana and Abousaarie (1993) and Cano-Garcia, Padilla-Munoz, and Carrasco-Ortiz (2005). according to (Dornyei 2005), a person, who is not agreeable possess characteristics of rude \&uncooperative behavior which leads to depersonalization. The hypothesis H3. E is presenting the positive but significant results of the relationship between neuroticism personality trait and depersonalization of university teachers. Since the regression weight, .786 with $\mathrm{p}<0.05$ indicates the positive influence of neuroticism personality trait on depersonalization. 
Hypothesis 4, investigated the association between personality traits and teachers' accomplishments. For the investigation of the $\mathrm{H} 4$ hypothesis, five sub-hypotheses were intended as follows. The outcome of the relationship between openness to experience personality traits and personal accomplishment was measured by hypothesis H4.A is found negative and insignificant through regression analysis which is supported by the $\mathrm{p}$-value $(\mathrm{P}>.05)$ at the regression weight -.019. It is validated that if the openness to experience personality trait of university teachers in District Peshawar enlarges by 1 unit, the personal accomplishment decrease by-.019. The hypothesis H4.B is presenting the negative insignificant results of the relationship between consciousness personality trait and personal accomplishment which is supported by the $\mathrm{p}$-value $(\mathrm{P}>.05)$ since the regression weight -.039 indicates the negative influence of consciousness on personal accomplishment and change of -.039in depersonalization occurs due to 1 unit change in consciousness. The results of hypothesis H4.C presented a positive and significant relationship of extroversion personality trait and personal accomplishment as $\mathrm{p}<0.05$ at regression weight .766 which implies that due to a 1 -unit increase in extroversion, the personal accomplishment will move upward by .766. Individuals who are not extroverts have attributes of calm \&less positive emotionality (Dornyei 2005) and (Whalen and Gates 2007). Such attributes reduce personal accomplishment \&further emotional exhaustion (Cano-Garcia, PadillaMunoz, \& Carrasco-Ortiz, 2005). The results of hypothesis H4.D indicate a negative and insignificant relationship between agreeableness personality trait and personal accomplishment at p $>0.05$ at regression weight -.194 which explains the inverse change of -.194 comes in personal accomplishment due to one unit upward change in an agreeableness personality trait. The hypothesis H4.E is presenting the negative but significant results of the relationship between neuroticism personality traits and personal accomplishment of university teachers. Since the regression weight, -.160 with $\mathrm{p}<0.05$ indicates the negative but significant influence of neuroticism personality trait on personal accomplishment. Neurotic people generally more vulnerable to burnout as they possess the attributes of insecurity, bad-tempered, and depression. Such attributes reduce personal accomplishment \&raise emotional exhaustion (Cano-García, Padilla-Muñoz, et al. 2005).

\section{CONCLUSION}

It was concluded by the researcher that a significant association between personality traits and teachers' burnout was found. Results showed that all five facets of personality did have a significant effect on university teachers' emotional exhaustion dimension of burnout. Results further revealed that of five personality dimensions, openness \& neuroticism personality dimensions do have a significant association with the depersonalization dimension of burnout. The present study results indicate that two traits of personality namely extroversion and neuroticism significantly affect personal accomplishment. Furthermore, it was identified that emotional intelligence significantly moderates the association between personality traits \& teachers' burnout. Additionally, it was found that female and private sector university teachers were more burnout than male and public sector university teachers respectively.

\section{LIMITATION, IMPLICATIONS, AND STUDY FORWARD}

This study is not free from limitations. Results of the current study cannot be generalized to school teachers as the current research only includes university teachers; further research can be conducted on secondary school teachers. It is recommended to conduct a comparative study of university teachers between public \& private sectors. Data were collected only from a few (317) respondents. It would be of some utility if this research is replicated on a larger sample.

Time and cost constraint is another limitation for this study. More time and financial resources can increase the generalization of the present study results. The current study is cross-sectional and longitudinal studies are recommended to explore the relationship between personality traits \& burnout. Chronological variations in burnout caused by personality can be recognized by longitudinal studies.

The researcher recommends using some moderators other than emotional intelligence such as perceived organizational support. Workers feel emotionally exhausted in a hectic situation \& support from the organization reduces burnout irrespective of personality traits.

The present study contributed to literature related to burnout, personality, and emotional intelligence among university teachers burnout in the teaching profession. University-level prevention programs about burnout and appropriate training and education to qualified teachers are recommended by university management to deal effectively with stressful situations. As far as practitioners are concerned, the present study recognizes personality traits more susceptible to exhaustion.

\section{ACKNOWLEDGEMENT}

All the praise and thanks to Allah Almighty and Muhammad (SAW).

\section{AUTHORS CONTRIBUTION}

All authors contributed equally in preparing this manuscript. First author contributing to suggesting the research idea as well as exploring current literature. The second author contributes to the analysis and interpretation of data. The third and fourth author concludes and reviews the whole paper respectively. 


\section{REFERENCES}

1 Ahola, K. and J. Hakanen (2007). Job strain, burnout, and depressive symptoms: A prospective study among dentists. Journal of affective disorders, 104(1-3), 103-110. https://doi.org/10.1016/j.jad.2007.03.004

2 Alarcon, G. E. KJ, \&Bowling, NA (2009). Relationship between Personality.

3 Bakker, A. B., et al. (2006). The relationship between the big five personality factors and burnout: A study among volunteer counselors. The Journal of social psychology, 146(1), 31-50. https://doi.org/10.3200/S OCP.146.1.31-50

4 Cano-García, F. J., et al. (2005). Personality and contextual variables in teacher burnout. Personality and Individual differences, 38(4), 929-940. https://doi.org/10.1016/j.paid.2004.06.018

5 Chirkowska-Smolak, T. (2009). Organizacyjne czynniki wypalenia zawodowego. cited from https://www.semanticscholar.org/paper/ORGANIZACYJNE-CZYNNIKI-WYPALENIA-ZAWODOWEGOChirkowskaSmolak/5bb7db6d7bb660bfc76b146eb57f0511a9933e02?sort=relevance \&citationIntent=backgroun $\underline{\mathrm{d}}$

6 Costa, P. T. and R. R. McCrae (1992). Normal personality assessment in clinical practice: The NEO Personality Inventory. Psychological assessment. 4(1), 5. https://doi.org/10.1037/1040-3590.4.1.5

7 de Looff, P., et al. (2018). Burnout symptoms in forensic psychiatric nurses and their associations with personality, emotional intelligence and client aggression: A cross-sectional study. Journal of psychiatric and mental health nursing, 25(8), 506-516. https://doi.org/10.1111/jpm.12496

8 Dikko, M. (2016). Establishing Construct Validity and Reliability: Pilot Testing of a Qualitative Interview for Research in Takaful (Islamic Insurance). Qualitative Report, 21(3). https://doi.org/10.46743/2160$\underline{3715 / 2016.2243}$

9 Dillman, D. A. (2007). Mail and Internet surveys: The tailored design method. Hoboken, NJ: John \& Wiley Sons, Inc.

10 Dornyei, Z. (2005). The psychology of the language learner: Individual differences in second language acquisition. New Jersey Mahwah.

11 Fisher, W. P. (2007). Rating scale instrument quality criteria. Rasch Measurement Transactions, 21(1), 1095.

12 Fontana, D. and R. Abouserie (1993). Stress levels, gender, and personality factors in teachers. British Journal of Educational Psychology, 63(2), 261-270. https://doi.org/10.1111/j.2044-8279.1993.tb01056.x

13 Gaś, Z. (2001). Doskonalacy się nauczyciel. Lublin: Wydawnictwo UMCS.

14 Gutierrez, D. and P. R. Mullen (2016). Emotional intelligence and the counselor: Examining the relationship of trait emotional intelligence to counselor burnout. Journal of Mental Health Counseling, 38(3), 187-200. https://doi.org/10.17744/mehc.38.3.01

15 Hakanen, J. J. and W. B. Schaufeli (2012). Do burnout and work engagement predict depressive symptoms and life satisfaction? A three-wave seven-year prospective study. Journal of affective disorders, 141(2-3), 415-424. https://doi.org/10.1016/j.jad.2012.02.043

16 Hall, L. H., et al. (2016). Healthcare staff wellbeing, burnout, and patient safety: a systematic review. PloS one, 11(7), e0159015. https://doi.org/10.1371/journal.pone.0159015

17 Heale, R. and A. Twycross (2015). Validity and reliability in quantitative studies. Evidence-based nursing, 18(3), 66-67. https://doi.org/10.1136/eb-2015-102129

18 Higuchi, Y., et al. (2016). A cross-sectional study of psychological distress, burnout, and the associated risk factors in hospital pharmacists in Japan. BMC Public Health. 16(1), 1-8. https://doi.org/10.1186/s12889-0163208-5

19 Joppe, M. (2000). The Research Process. Retrieved February 25, 1998. https://www.researchgate.net/pu blication/3191 28421_Validity_Reliability_Generalizability

20 Kaushik, M. and B. Mathur (2014). Data analysis of students marks with descriptive statistics. International Journal on Recent and Innovation Trends in computing and communication, 2(5), 1188-1190.

21 Kirenko, J. and T. Zubrzycka-Maciąg (2011). Współczesny nauczyciel: studium wypalenia zawodowego, Wydawnictwo Uniwersytetu Marii Curie-Skłodowskiej.

22 Komarraju, M., et al. (2011). The Big Five personality traits, learning styles, and academic achievement. Personality and individual differences, 51(4), 472-477. https://doi.org/10.1016/j.paid.2011.04.019

23 Krejcie, R. V. and D. W. Morgan (1970). Determining sample size for research activities. Educational and psychological measurement, 30(3), 607-610. https://doi.org/10.1177/001316447003000308

24 Lindeman, B., et al. (2017). Association of burnout with emotional intelligence and personality in surgical residents: can we predict who is most at risk? Journal of surgical education, 74(6), e22-e30. https://doi.org/10.1016/j.jsurg.2017.11.001

25 Molavynejad, S., et al. (2019). Relationship between personality traits and burnout in oncology nurses. Journal of family medicine and primary care, 8(9), 2898. https://doi.org/10.4103/jfmpc.jfmpc $423 \_19$

26 Muijs, D. (2010). Doing quantitative research in education with SPSS, Sage. https://doi.org/10.4135/ 9781849203241

27 Pandey, N. and M. Kavitha (2015). Relationship between Teachers' personality traits and self-efficacy: an empirical analysis of school teachers in Karaikal region. Pacific Business Review International, 8(3), 37-42. 
28 Polit, D. Beck. CT, Hungler, BP (2001) Essentials of nursing research: methods, appraisal, and utilization, Philadelphia: Lippincott.

29 Poropat, A. E. (2009). A meta-analysis of the five-factor model of personality and academic performance. Psychological Bulletin, 135(2), 322. https://doi.org/10.1037/a0014996

30 Prins, D. J., et al. (2019). The relationship between burnout, personality traits, and medical specialty. A national study among Dutch residents. Medical teacher, 41(5), 584-590. https://doi.org/10.1080/0142159X.201 8.1514459

31 arıçam, H. and H. Sakız (2014). Burnout and teacher self-efficacy among teachers working in special education institutions in Turkey. Educational Studies, 40(4), 423-437. https://doi.org/10.1080/03055698.2014.930340

32 Savas, A. C., et al. (2014). A Study on the Relationship between Teacher Self Efficacy and Burnout. European Journal of Educational Research, 3(4), 159-166. https://doi.org/10.12973/eu-jer.3.4.159

33 Schultz, D. P. and S. E. Schultz (2016). Theories of personality, Cengage Learning.

34 Sekaran, U. and R. Bougie (2016). Research methods for business: A skill-building approach, John Wiley \& Sons.

35 Shakeel, S., et al. (2021). Linking Personality Traits, Self-Efficacy and Burnout of Teachers in Public Schools: Does School Climate Play a Moderating Role? Public Organization Review, 1-21. https://doi.org/10.1007/s 11115-021-00514-8

36 Skodova, Z. and P. Lajciakova (2013). The effect of personality traits and psychosocial training on burnout syndrome among healthcare students. Nurse Education Today, 33(11), 1311-1315. https://doi.org/10.1016/j.n edt.2013.02.023

37 Sulea, C., et al. (2015). Engagement, boredom, and burnout among students: Basic need satisfaction matters more than personality traits. Learning and Individual Differences, 42, 132-138. https://doi.org/10.1016/j.1 indif.2015.08.018

38 Toker, S. and M. Biron (2012). Job burnout and depression: unraveling their temporal relationship and considering the role of physical activity. Journal of Applied Psychology, 97(3), 699. https://doi.org/10.10 37/a0026914

39 Tucholska, S. (2008). Zjawisko hazardu patologicznego i jego uwarunkowania. Roczniki psychologiczne, 11(2), 45-68.

40 van der Wal, R. A., et al. (2016). Psychological distress, burnout and personality traits in Dutch anaesthesiologists: a survey. European Journal of Anaesthesiology (EJA), 33(3), 179-186. https://doi.org/10.1 097/EJA.0000000000000375

41 Whalen, T. and C. Gates (2007). A psychological profile of defender personality traits. Journal of Computers, 2(2), 84-93. https://doi.org/10.4304/jcp.2.2.84-93

42 Zawadzka, A. S., et al. (2018). The Big Five and burnout among teachers: the moderating and mediating role of self-efficacy. Polish Psychological Bulletin, 49(2). 